\title{
Assessment of $\mathrm{VO}_{2} \mathrm{max}$ between Bharatanatyam and Kuchipudi Dancers
}

\author{
Siva Jyothi $\mathbf{N}^{1}$, Senthil Selvam $P^{2}$, Gopaldas Ramesh ${ }^{3}$, Yatheendra Kumar $G^{4}$ \\ ${ }^{1}$ Research Scholar, School of Physiotherapy, VELS University, Chennai. \& Associate Professor, Department of \\ Cardio and Pulmonary Physiotherapy, Durgabai Deshmukh College of Physiotherapy, DDMS (AMS), \\ Hyderabad, Telangana, India.. \\ ${ }^{2}$ Principal/ HOD School of Physiotherapy, VELS University, Chennai. \\ ${ }^{3}$ Master of Physiotherapy, Durgabai Deshmukh College of Physiotherapy, Hyderabad, Telangana. \\ ${ }^{4}$ Vice Principal, Susruta Institute of Physical Medicine and Rehabilitation, Hyderabad, Telangana, India \\ Corresponding Author: Siva Jyothi N
}

\begin{abstract}
Dance is the good form of exercise, the movement of the body in a rhythmic way to music and within a given space, for the purpose of expressing an idea or emotion, releasing energy, or simply taking delight in the movement itself which the body is capable. Though Bharatanatyam and Kuchipudi may look similar to the untrained eye, there are many differences which affect the mechanics of movement among practitioners of both art forms. The purpose of this study is to assess the vo2 max of Bharatanatyam and Kuchipudi dancers and to find out whether there is any difference in the vo2 max between both the dancers. Total of 30 subjects who met the inclusion criteria were taken for study; Group A ( $n=15)$ Bharatanatyam dancers. Group B ( $n=15)$ Kuchipudi dancers. Queen's college step test was used to assess the vo2 max. Pre and post-test heart rate was measured and vo2 max calculated. Statistical analysis was tested with $t$ test at $95 \%$ level of significance $(p<0.05)$. The result of the present study suggests that there is no significant difference in the aerobic capacity among Bharatanatyam (Group A) and Kuchipudi (Group B) Dancers when assessed with Queen's College Step test.
\end{abstract}

Key Words: Bharatanatyam, Kuchipudi, Cardio respiratory fitness, VO2 max, Queen's college step test.

\section{INTRODUCTION}

In the recent medical literature, Dance in its many forms has received much attention for the physical fitness. The increasing evidences in the literature has linked the cardiovascular diseases to lack of activity, reduced cardiopulmonary fitness and obesity. ${ }^{1}$ Regular exercises helps in attaining / maintaining the benefits to health. Regular physical activity and proper exercise session are to be encouraged. The participants should be able to enjoy the form of exercise and should be able to practice regularly to improve their physical fitness level. Gymnastics, figure skating and synchronized swimming are sports that incorporate dance, while martial arts, kata are often compared to dances. ${ }^{2}$ Dance is a non-competitive form of exercise that has shown a positive effects on physical health as well as mental and emotional wellbeing. Now a days in many hospitals and medical settings it has been used as a form of therapy not only for mental health but also for physical health. ${ }^{3}$

The physiological response to dance is dependent on the intensity, duration and frequency of the exercise as well as the environmental conditions. During dance practice, oxygen and substrate requirement is increased at the skeletal muscle and also the removal of metabolites and carbon 
dioxide is also increased. Chemical, mechanical and thermal stimuli affect alterations in metabolic, cardiovascular and ventilator function in order to meet these increased demands. A good dancer should be able to perform well-co-ordinated, controlled balanced movements. Endurance is essential to continue prolonged dance performance to develop awareness of space, a strong sense of rhythm, and an appreciation of music. Particularly in theatrical dance, the dancer must be able to project movement clearly and make its expressive qualities intelligible to the audience. Grace, fluidity, and the harmony of the body are also frequently desired in the dancer, as is physical beauty. ${ }^{2}$

Bharatanatyam is one of many forms of Indian classical dance that originated in Tamil Nadu, a region of southern India. ${ }^{4}$ The term Bharatanatyam is broken up into four components: Bha for Bhava (expression), Ra for Raga (music), Ta for Tala (rhythm), and Natya (dance). Bharatanatyam encompasses all the traditional aspects of classical dance: the mudras (hand positions), abhinaya (facial expressions), and padams (narrative dances). In Bharatanatyam dance form the dancers make considerable use of hand-and-eye movements to express different emotion. ${ }^{3}$ It is an amalgamation of emotion, music, rhythm and expression. Bharatanatyam is mudra oriented and gives importance to padartha abhinaya, each word interpreted through mudras. In navarasa parts (nine sentiments) the dancers expresses their inner feelings and it helps to release their emotions. $^{5}$

Kuchipudi is an Indian classical dance form originated from Andhra Pradesh, a State of South India. The dance form attained perfection by the time of Golconda king Abdul Hassan Tanesha. The movements in Kuchipudi are quicksilver and scintillating, rounded and fleet-footed. Kuchipudi dance is vachika abhinaya (based on dialogues) oriented. It also highlights the therapeutics as was followed in Natyashastra more than any other dance form in India. Each aspect of abhinaya or the expressive means is given a detailed description in this dance. This dance requires proper body balance. The therapeutic effects of this dance form are embedded in its grace and fluid movements. ${ }^{3}$

Dancing is an excellent way to improve physical fitness, a set of attributes that are either health or skill-related and develop social skills, as a result to improving mental health.

The positive effects of dance on physical fitness that observed in various areas like flexibility, strength and endurance. In recent studies, increasing the heart rate up to $65-85 \%$ by workout of dance fitness. It does not beneficial only for cardiovascular health but also helps for shape of body and weight loss. ${ }^{6}$

Although differences exist between dance and sporting activity, dance execution is not a single act it forms of athletic activity depending on a huge number of rudiments with direct and indirect effects. Physical fitness may be defined as an individual's ability to meet demands of a specific physical task. As in most sports dance fitness depends on the individual's ability to work under aerobic and anaerobic conditions, and on their capacity to develop high levels of muscle tension and muscle strength. The joint mobility and flexibility are also important parts of dance fitness. However no single fitness measurement can predict success in dance, as they vary markedly depending on numerous parameters including age, sex, and level of performance. ${ }^{3}$

The maximum oxygen uptake [vo2 max], an internationally accepted parameter to evaluate the cardio respiratory fitness reflects the amount of oxygen utilized by working muscles during maximal exercise. It is the best index of aerobic capacity and gold standard for cardio respiratory fitness. Thus measure of maximum oxygen consumption offer insight into ability of cardiovascular, respiratory and muscular system to deliver and utilize oxygen. During 
exercise, up to a point the increase in oxygen consumption is proportionate to energy expended and all the energy needs are met my aerobic process. So in a person, the more is the maximum oxygen consumption capacity $\left[\mathrm{VO}_{2 \max }\right]$, the more will be his/ her aerobic capacity. VO2max is the measure of the functional limit of the cardio-respiratory system and the single most valid index of maximal exercise capacity.

Decrease in VO2 max is therefore an indicator of reduced exercise capacity or tolerance. It is the product of maximum cardiac output and maximal arterio-venous oxygen difference. As direct estimation of $\mathrm{VO}_{2 \max }$ is exhaustive, laborious and difficult experimental protocol, a reliable indirect method was followed for prediction of $\mathrm{VO}_{2 \max }{ }^{7}$

Step test is one of the most widely used field tests for estimating $\mathrm{VO}_{2 \mathrm{MAX}}$. Stepping requires no elaborate or expensive equipment, no calibration, and can be easily administered to large number of people. Most commonly administered step test are performed at a cadence on a bench of a fixed height. One such test is the Queen's college step test. Queen's college step test is one of many variations of test procedures used to determine aerobic fitness. This test has a lower step height, slower cadence, and more simple analysis. This submaximal test provides a measure of cardio respiratory or respiratory fitness. ${ }^{8}$ The purpose of our study was to assess and compare the level of physical fitness among Bharatanatyam and Kuchipudi dancers.

\section{MATERIALS AND METHODS}

PROCEDURE: This comparative study was conducted on 30 participants at Sudipta dance school, Hyderabad after obtaining approval from institutional ethical committee. The informed consent was taken from all the participants of the study. The subjects were randomly selected according to inclusion criteria (Age: 15-25 years, Females, Bharatanatyam dancers and kuchipudi dancers (Minimum regular 6 months training with at least one session of one and half to two hours duration and minimum three days in a week) and exclusion criteria (Cardio pulmonary problems, Myocardial infarction, Cardiac arrhythmia, Acute endocarditis, Any respiratory problems, Musculoskeletal problems, Subjects who did not give consent).

Subjects were grouped into two groups based on non-probability convenience sampling taking on same age group. GROUP 'A' - Bharatanatyam Dancers-15 subjects and GROUP 'B'Kuchipudi Dancers-15 subjects.

\section{METHODOLOGY PROCEDURE}

Queen's college step test is one of the many variations of step test procedures, used to determine aerobic fitness.

Purpose: This submaximal test provides a measure of cardio respiratory or endurance fitness.

After meeting inclusion criteria, Informed consent is taken from dancers. Made to rest for 5 minutes. Resting HR is measured. Procedure is explained to the dancers. The dancer should warm up for 10 minutes. In the procedure the dancer should step up and down for 3 minutes at a rate of 22 steps per minute. Therapist gives command go and starts stop watch and dancer commences the test. We should ensure that dancer should maintain 22 steps per minute. Then the therapist should stop the test after 3 minutes. Then we have to count dancer heart rate for 15 seconds and multiply this 15 seconds reading by 4 will give the beats per minute value to be used in the below calculation

Women: $\quad \mathrm{VO}_{2 \mathrm{MAX}} \quad[\mathrm{ml} / \mathrm{kg} / \mathrm{min}]=65.81-$ [0.1847×post HR bpm] ${ }^{9}$

The queen college step test is done in both Bharatanatyam (Group A) and Kuchipudi dancers (Group B). $\mathrm{VO}_{2 \mathrm{MAX}}$ is calculated for both the groups. Pre and Post values of $\mathrm{HR}$ and $\mathrm{VO}_{2 \mathrm{MAX}}$ are compared between both the groups. 


\section{STATISTICAL ANALYSIS AND RESULTS}

Statistical analysis was performed by using SPSS statistical software. The scores were analysed using statistical tests. Mean, standard deviation of all the values were calculated. The observed differences were tested with the $t$ at $95 \%$ level of significance. Statistically the inter group results are compared by Independent $t$ test;
Intra group results are compared by Paired t test.

\section{BHARATNATYAM (GROUP A)}

TABLE 1: This table is calculating pre and post values of mean, standard deviation, standard error mean of HR rate in Group A

\begin{tabular}{|l|l|l|l|l|l|}
\hline & & Mean & N & $\begin{array}{l}\text { Std. } \\
\text { Deviation }\end{array}$ & $\begin{array}{l}\text { Std. Error } \\
\text { Mean }\end{array}$ \\
\hline Pair & HR_Pre & 76.0000 & 15 & 3.20713 & .82808 \\
\cline { 2 - 5 } 1 & HR_Post & 94.9333 & 15 & 12.78094 & 3.30002 \\
\hline
\end{tabular}

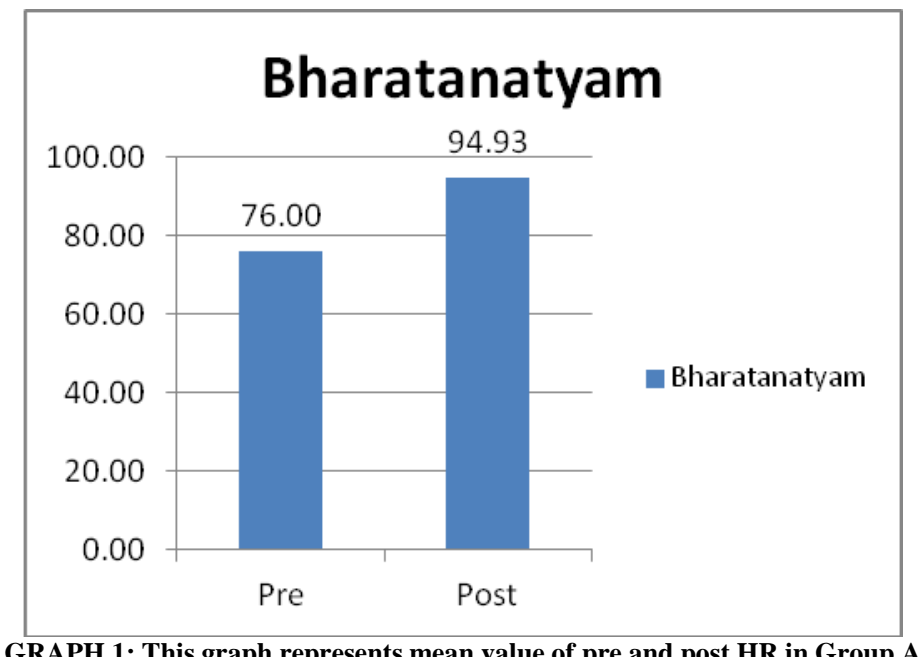

TABLE 2: This table is calculating paired differences of pre and post HR in Group A

\begin{tabular}{|c|c|c|c|c|c|c|c|}
\hline & & \multicolumn{3}{|c|}{ Paired Differences } & \multirow[t]{2}{*}{$\mathbf{T}$} & \multirow[t]{2}{*}{ Df } & \multirow{2}{*}{ Sig. (2-tailed) } \\
\hline & & Mean & Std. Deviation & Std. Error Mean & & & \\
\hline Pair 1 & HR_Pre - HR_Post & -18.93333 & 12.32574 & 3.18249 & -5.949 & 14 & .000 \\
\hline
\end{tabular}

\section{KUCHIPUDI (GROUP B)}

TABLE 3: This table is calculating mean, standard deviation, standard error mean of pre and post HR in Group B

\begin{tabular}{|l|l|l|l|l|l|}
\hline \multicolumn{2}{|c|}{ Paired Samples Statistics } \\
\hline & & Mean & N & Std. Deviation & Std. Error Mean \\
\hline \multirow{2}{*}{ Pair 1 } & HR_Pre & 74.0000 & 15 & 3.54562 & .91548 \\
\cline { 2 - 6 } & HR_Post & 88.5333 & 15 & 8.79827 & 2.27170 \\
\hline
\end{tabular}

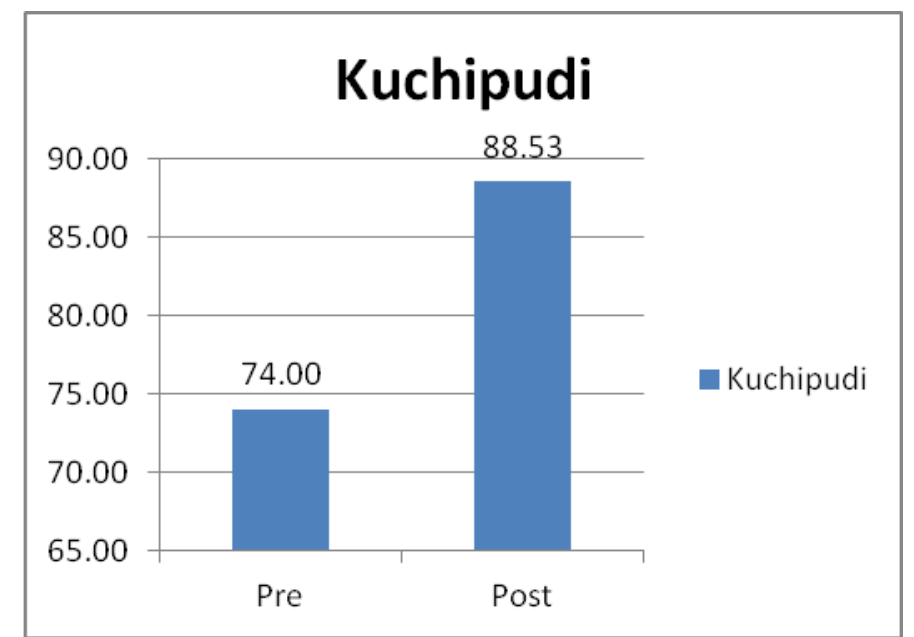

GRAPH 2: This graph represents mean value of pre and post HR in Group B 
TABLE 4: This table is calculating paired differences of pre and post HR in Group B

\begin{tabular}{|c|c|c|c|c|c|c|c|}
\hline & & \multicolumn{3}{|c|}{ Paired Differences } & \multirow[t]{2}{*}{$\mathbf{T}$} & \multirow[t]{2}{*}{ Df } & \multirow[t]{2}{*}{ Sig. (2-tailed) } \\
\hline & & Mean & Std. Deviation & Std. Error Mean & & & \\
\hline Pair 1 & HR_Pre - HR_Post & -14.53333 & 8.50098 & 2.19494 & -6.621 & 14 & .000 \\
\hline
\end{tabular}

As can be seen from the output, a significant difference between Pre and Post in Kuchipudi. Since t-test value is -6.621 and its p-value 0.0001 is less than 0.05 .

\section{GROUP A COMPARED WITH GROUP B}

TABLE 5: This table is calculating mean,standard deviation and standard error mean of pre and post HR between Group A and Group B

\begin{tabular}{|l|l|l|l|l|l|}
\hline \multicolumn{6}{|l|}{ Group Statistics } \\
\hline & Group & N & Mean & Std. Deviation & Std. Error Mean \\
\hline \multirow{2}{*}{ HR_Pre } & Bharatanatyam & 15 & 76.0000 & 3.20713 & .82808 \\
\cline { 2 - 6 } & Kuchipudi & 15 & 74.0000 & 3.54562 & .91548 \\
\hline \multirow{2}{*}{ HR_Post } & Bharatanatyam & 15 & 94.9333 & 12.78094 & 3.30002 \\
\cline { 2 - 6 } & Kuchipudi & 15 & 88.5333 & 8.79827 & 2.27170 \\
\hline
\end{tabular}

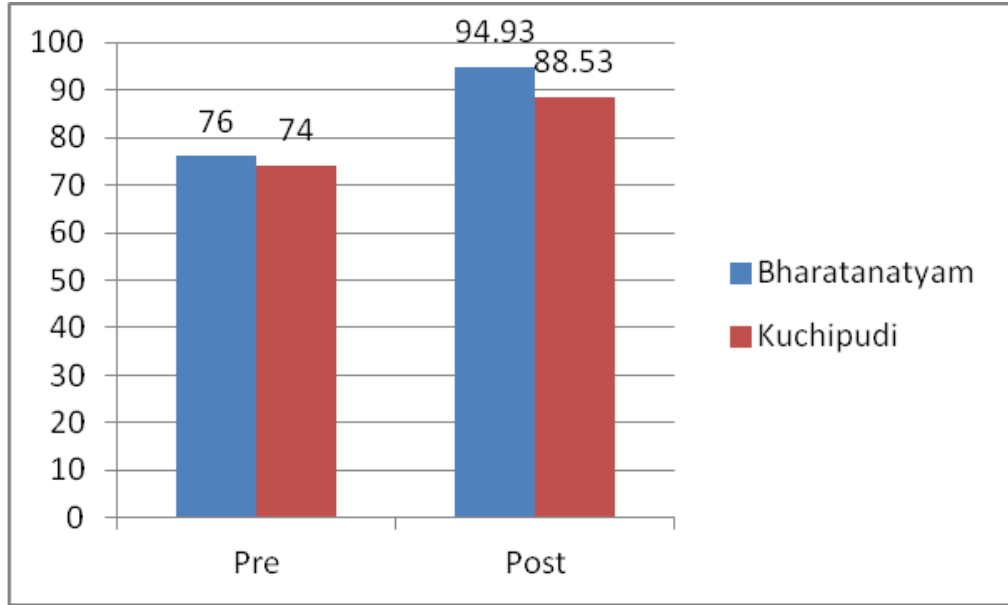

GRAPH 3: This graph represents mean value of pre and post HR between Group A and Group B

\begin{tabular}{|l|l|l|l|l|l|l|}
\hline TABLE 6: This table is calculating t-test for equality of means for HR between Group A and Group B \\
\hline & & t-test for Equality of Means & \\
\hline & & t & df & Sig. (2-tailed) & Mean Difference & Std. Error Difference \\
\hline HR_Pre & Equal variances assumed & 1.620 & 28 & .116 & 2.00000 & 1.23443 \\
\hline HR_Post & Equal variances assumed & 1.597 & 28 & .121 & 6.40000 & 4.00634 \\
\hline
\end{tabular}

As can be seen from the output, not significant difference between Bharatanatyam and Kuchipudi in Pre. Since t-test value is 1.620 and its p-value 0.116 is greater than 0.05 .

As can be seen from the output, not significant difference between Bharatanatyam Kuchipudi inPost. Since t-test value is 1.597 and its p-value 0.121 is greater than 0.05 .

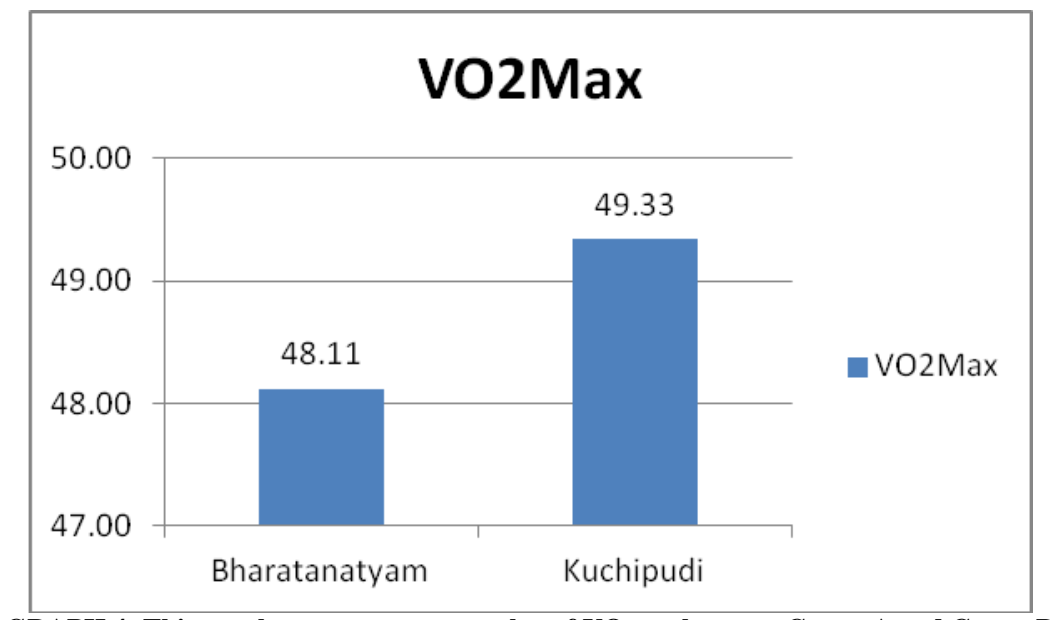

GRAPH 4: This graph represents mean value of $\mathrm{VO}_{2 \mathrm{MAX}}$ between Group $\mathrm{A}$ and Group $\mathrm{B}$ 
TABLE 7: This table is calculating mean, standard deviation, standard error mean for $\mathrm{VO}_{2 \mathrm{MAX}}$ between Group A and Group B

\begin{tabular}{|l|l|l|l|l|l|}
\hline \multicolumn{6}{|c|}{ Group Statistics } \\
\hline & Group & N & Mean & Std. Deviation & Std. Error Mean \\
\hline VO2Max & Bharatanatyam & 15 & 48.1143 & 2.31326 & .59728 \\
\cline { 2 - 6 } & Kuchipudi & 15 & 49.3347 & 1.68499 & .43506 \\
\hline
\end{tabular}

TABLE 8: This table is calculating t-test for equality of means for $\mathrm{VO}_{2 \mathrm{MAX}}$ between Group $\mathrm{A}$ and Group B

\begin{tabular}{|l|l|l|l|l|l|l|}
\hline & \multicolumn{7}{|c|}{ t-test for Equality of Means } \\
\hline & & T & df & Sig. (2-tailed) & Mean Difference & Std. Error Difference \\
\hline VO2Max & Equal variances assumed & -1.652 & 28 & .110 & -1.22047 & .73893 \\
\hline
\end{tabular}

As can be seen from the output, No significant difference between Bharatanatyam and Kuchipudi in VO2Max. Since t-test value is -1.652 and its p-value 0.110 is greater than 0.05 .

\section{DISCUSSION}

Assessment of $\mathrm{VO}_{2 \mathrm{MAX}}$ in Bharatanatyam dancers and Kuchipudi dancers through Queen's College Step Test showed no significant difference between both groups.

Table $1 \& 2$ shows that there is increase in post values of Heart rate compared to pre values in Group A (Bharatanatyam Dancers). Table $3 \& 4$ shows increase in post values of Heart rate compared to pre values in Group B (Kuchipudi Dancers). Queen's College step test is a submaximal exercise test, when it is performed there is increase in heart. Exercising at a steady pace for a prolonged period will cause heart rate to increase. Heart rate increases when begin to exercise, then plateaus off and remains elevated for a prolonged period as long as you maintain same pace. If you increase your effort, it will go even higher until you reach your maximal capacity. The quick responsiveness of your heart to exercise is due to the demand for oxygen in your muscles.

\section{VO $_{2 \mathrm{MAX}}$ (Aerobic Capacity)}

Table $7 \& 8$ shows observed values aerobic capacity between both the groups. There is no significant difference between both the groups.

Bharatanatyam is one of the most sublime of the Indian classical dancers .It emerged in Tanjore of Tamilnadu. Bharatanatyam encompasses all the traditional aspects of classical dance the hand positions, facial expressions narrative dances. In Bharatanatyam dance form the dancers make considerable use of hand and eye movements to express different emotions .It is an amalgamation of emotion, music rhythm and expression. The dancer expresses their inner feelings and also it helps to release their emotions. This Bharatanatyam dance strengthens the hamstring muscles including semitendinosus, semimembranosus, biceps femoris etc. ${ }^{3}$

Kuchipudi is an Indian classical dance form originated from Andhra Pradesh. This dance requires proper body balance. The therapeutic effects of this dance form are embedded in its grace and fluid movements. The survey conducted with the dancers showed strong effect of some muscles including rectus abdominis, abdominal external oblique, latissimus dorsi, gluteal maximus, etc. ${ }^{3}$

Queen's College Step test is currently the test of choice while using for Clinical or Research purposes. This study was undertaken to provide a statistical data regarding any variation in amount of aerobic capacity in Bharatanatyam and Kuchipudi Dancers. All the subjects were of the same sex and same age, weight group thereby eliminating the possible interaction of such factors.

The two study groups i.e., Bharatanatyam Dancers (Group A) and Kuchipudi Dancers (Group B) were matched for age, sex and weight. They only differed in the form of classical dance form.

$$
\mathrm{VO}_{2 \mathrm{MAX}} \quad \text { (Maximal oxygen }
$$

Consumption, Maximal oxygen uptake, peak oxygen uptake or maximal aerobic capacity) is the maximum capacity of an individual's body to transport and use 
oxygen during incremental exercise, which reflects the physical fitness of the individual. The maximum oxygen uptake $\left[\mathrm{VO}_{2 \mathrm{max}}\right]$, an internationally accepted parameter to evaluate the cardio respiratory fitness reflects the amount of oxygen utilized by working muscles during maximal exercise. It is the best index of aerobic capacity and gold standard for cardio respiratory fitness. Thus measure of maximum oxygen consumption offer insight into ability of cardiovascular, respiratory and muscular system to deliver and utilize oxygen. During exercise, up to a point the increase in oxygen consumption is proportionate to energy expended and all the energy needs are met my aerobic process. So in a person, the more is the maximum oxygen consumption capacity $\left[\mathrm{VO}_{2 \max }\right]$, the more will be his/ her aerobic capacity. $\mathrm{VO}_{2 \max }$ is the measure of the functional limit of the cardio-respiratory system and the single most valid index of maximal exercise capacity. ${ }^{8}$

Shankarashis Mukherjee et al. concluded that receiving training in Bharatanatyam dancing, for at least a period of five years, facilitates females in achieving healthier body composition and increase physical fitness and thus consequently reducing the probability of cardiovascular risk factors. ${ }^{10}$

Sabaananth et al., stated that, Aerobic Bharatanatyam and Kandyan dancers are effective methods to improved pulmonary function in respect of vital capacity for female dancers. ${ }^{2}$

K. Bharathi et al done study comparing the significance of anthropometric parameters on aerobic capacity among dancers. This study was attempted to compare the body mass index and waist-hip ratio on aerobic capacity in Hip-Hop dancers and Indian classical dancers. According to the results, there is no significant difference in body mass index on aerobic capacity $\left(\mathrm{VO}_{2 \max }\right)$ of the Indian classical dancers $(p=0.320)$ and hip-hop dancers $(\mathrm{p}=0.940)$. According to the results, there is no significant difference in waist- hip ratio on aerobic capacity $\left(\mathrm{VO}_{2 \max }\right)$ of the Indian classical dancers $(\mathrm{p}=0.030)$ and hiphop dancers $(\mathrm{p}=0.170)^{11}$

Laalithya Konduru done a study on the health benefits of Kuchipudi dance An Indian classical dance-based intervention to manage musculoskeletal injury and psychological distress in young and otherwise healthy individuals Twenty-one healthy young individuals filled out a questionnaire assessing their level of psychological distress, problems with neuromuscular coordination, and level of disability from lower back pain. They then underwent structured training in Kuchipudi dance for 6 months. At the end of 6 months, the same questionnaire was administered again, and the pre-and post-intervention scores were compared. There was a statistically significant reduction in the scores of all domains tested and concluded that recreational Kuchipudi dance is shown to have beneficial effects on physical and psychological disability. ${ }^{12}$

It is common notion that only physical exercise provides physical fitness and is beneficial to health. But it is found that any type of physical activity done regularly can improve cardiovascular endurance. Indian classical dance is one of the physical activities as it is done regularly. ${ }^{1}$ The $\mathrm{VO}_{2 \mathrm{MAX}}$ (Aerobic capacity) grading of both groups lies in "above average" category. Thus physical activity like Indian Classical dance done regularly improved aerobic capacity/cardiovascular endurance in dancers. Therefore this the reason why Bharatanatyam dancers and Kuchipudi Dancers have same level of aerobic capacity $\left(\mathrm{VO}_{2 \mathrm{MAX}}\right)$.

\section{Limitations and Recommendations:}

Study can be conducted by taking a large sample size, the study was conducted on only female dancers. Further study can be done on male population and also on various other dancers. 


\section{CONCLUSION}

The result of the present study suggests that there is no significant difference in the aerobic capacity among Bharatanatyam (Group A) and Kuchipudi (Group B) Dancers when assessed with Queen's College Step test. There is significant difference in Post HR values compared to Pre HR followed by Queen's College Step test in Group A and Group B, but no significant change in $\mathrm{HR}$ and $\mathrm{VO}_{2 \mathrm{MAX}}$ between both the groups

\section{Acknowledgement: None}

\section{Conflict of Interest: None}

\section{Source of Funding: None}

\section{Ethical Approval: Approved}

\section{REFERENCES}

1. Gaikwad RB, Waghmare VK, Shenvi DN. Aerobic Capacity in Regular Physical Exercise Group and Indian Classical Dancers: A Comparative Study. Indian Journal of Physiotherapy and Occupational Therapy. 2013;7(1):238.

2. Sabaananth S, Gopinath V, Thevanthy T. Effect of different dance training on vital capacity among post-pubescent girls. International journal of multidisciplinary studies. Volume 01, issue 01-2014 [13]

3. Chatterjee A. The therapeutic value of Indian classical, folk, and innovative dance forms. Rupkatha J Interdisc Studies Hum. 2013 Jan 1;5(1):75-83.

4. Pillai S. Rethinking global Indian dance through local eyes: The contemporary Bharatanatyam scene in Chennai. Dance Research Journal. 2002 Dec 1;34(2):14-29.

5. Balaji Deekshitulu P V. Physical \& Mental Health for Indian Classical Dance.
American Journal of History and Culture, 2019,2:9.

6. Thomas C. Role of Dance in Body Fitness. Academic journal of dance and music. Volume 01 | Issue 01 | June-2018 | Page 1618

7. Nabi T, Rafiq N, Qayoom O. Assessment of cardiovascular fitness [VO2 max] among medical students by Queens College step test. Int J Biomed Adv Res. 2015;6(5):41821.

8. Shamsi MM, Alinejad HA, Ghaderi M, Badrabadi KT. Queen's college step test predicted VO2max: The effect of stature. Annals of Biological Research. 2011;2(6): 371-7.

9. Divya Khare, Mohini Sharma. To determine the correlation of recovery pulse rate and VO2max on performance of Queen's College step test in young adult Indian females. International Journal of Medical and Health Research Volume 3; Issue 7; July 2017; Page No. 01-05

10. Mukherjee S, Banerjee $\mathrm{N}$, Chatterjee S. Effect of Bharatanatyam dancing on body composition and physical fitness status of adult Bengalee females. Indian journal of biological sciences. Vol18 (2012).

11. Keerthiga L. Influence of Anthropometric Parameters on Aerobic Capacity among Dancers. International Journal of Innovative Science and Research Technology. Volume 4, Issue 7, July - 2019

12. Konduru L. The Health Benefits of Kuchipudi Dance. AMSA Journal of Global Health. 2020 May 31;14(1):62-8.

How to cite this article: Siva Jyothi N, Senthil Selvam P, Ramesh G et.al. Assessment of $\mathrm{Vo}_{2 \max }$ between bharatanatyam and kuchipudi dancers. Int J Health Sci Res. 2021; 11(5): 188195. DOI: https://doi.org/10.52403/ijhsr. 20210529 